\title{
Does fasting in Ramadan increase the risk of developing urinary stones?
}

Abdullab O. Al Mahayni, Medical Student, Sultan S. Alkhateeb, MD, Ibrahim H. Abusaq, MBBS,

Abdullah A. Al Mufarrih, Medical Intern, Muath I. Jaafari, Medical Student, Amen A. Bawazir, PhD.

$$
\begin{aligned}
& \text { ABSTRACT } \\
& \text { الأهداف : استكشاف نسبة حدوث الحصوات البولية في رمضان }
\end{aligned}
$$

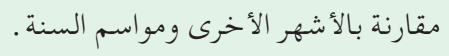

$$
\begin{aligned}
& \text { الطريقة: أجريت دراسة مستعرضة بأثر رجعي باستخدام }
\end{aligned}
$$

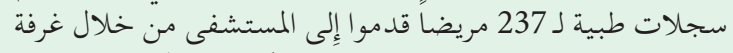

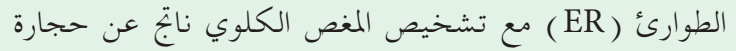

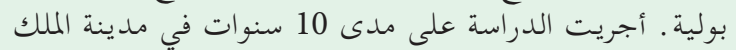

$$
\begin{aligned}
& \text { عبد العزيز الطبية، الرياض، المملكة العربية العلى مدئ السعودية. } \\
& \text { النتائج: المرضى القادمون في رمضان هم أكثر عرضة مرتين }
\end{aligned}
$$

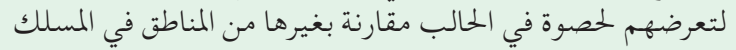

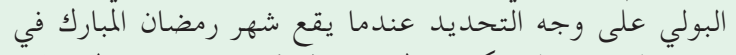

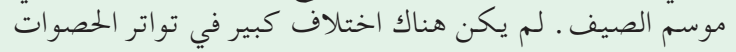

$$
\begin{aligned}
& \text { البولية بين رمضان وغير شهر رمضان ليكن هيناك اختلان } \\
& \text { الحاتمة: الصيام في شهر رمضان لا يزيد من خطر الأبر حدوث }
\end{aligned}
$$

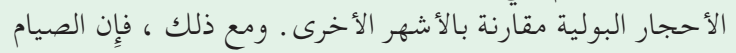

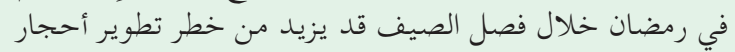

$$
\begin{aligned}
& \text { الحَّالب مقارنة بالصيام في رمضان فلان خلال فصل فصل الشتاء. }
\end{aligned}
$$

Objectives: To explore the frequency of renal colic (RC) secondary to urinary stones in Ramadan compared to other months and seasons of the year.

Methods: Retrospective cross-sectional study using medical records of 237 patients admitted through the emergency room (ER) with a diagnosis of RC secondary to urinary stones over a 10 -year period at King Abdulaziz Medical City, Riyadh, Kingdom of Saudi Arabia.

Results: Patients fasting in Ramadan are 2 times more likely to present with a calculus of ureter as opposed to calculus in another location in the urinary tract, particularly when the holy month of Ramadan falls in the summer season. There was no significant difference in the frequency of urinary stones between Ramadan and non-Ramadan months.
Conclusion: Fasting in Ramadan does not increase the risk for developing urinary stones compared to nonfasting months. However, fasting in Ramadan during the summer may increase the risk of developing ureter stones compared to fasting in Ramadan during the winter.

Saudi Med J 2018; Vol. 39 (5): $481-486$ doi: $10.15537 /$ smj.2018.5.22160

From the College of Medicine (Al Mahayni, Jaafari), from the College of Public Health and Health Informatics (Bawazir), King Saud bin Abdulaziz University for Health Sciences; from the Department of Urology (Alkhateeb), King Abdulaziz Medical City; from the College of Medicine (Al Mufarrih), Al Maarefa Colleges, Riyadh, and from the College of Medicine (Abu-Saq), King Khalid University, Abha, Kingdom of Saudi Arabia.

Received 19th February 2018. Accepted 11th April 2018.

Address correspondence and reprint request to: Dr. Abdullah $O$. Al Mahayni, College of Medicine, King Saud bin Abdulaziz University for Health Sciences, Riyadh, Kingdom of Saudi Arabia. E-mail: almahayni044@ksau-hs.edu.sa

ORCID ID: orcid.org/0000-0003-1838-2986

$\mathrm{R}$ amadan is a holy month within the Islamic lunar calendar, where all Muslims are required to fast (abstain from food and drink) during the daytime (from sunrise to sunset) for the entire month. ${ }^{1}$ Some studies have reported metabolic changes associated with fasting like weight loss, dehydration, and increased serum and urine concentrations of uric acid. However, these changes are not likely to have significant harmful consequences on healthy individuals. ${ }^{2-5}$ A few studies have investigated the association between the incidence of urinary tract colic due to urinary tract stones and Ramadan. Most of these studies showed no significant association between the incidence of urinary tract stones and Ramadan. ${ }^{6-8}$ However, these studies were carried out over a short period of time, and did not take into consideration the seasonal variations in which Ramadan 
occurs (for instance, summer or winter based on lunar calendar variation). Ramadan may occur in any season of the year because a year in the lunar calendar is 11 days shorter than a year in the Gregorian calendar. Therefore, a question was raised as to whether fasting in Ramadan increases the risk of developing urinary tract stones in different seasons of the year (particularly summer versus winter). Currently there is still debate over whether fasting during Ramadan is associated with the occurrence of urinary tract stones or not. As an example, Miladipour et $\mathrm{al}^{8}$ did not find a significant association between Ramadan and urinary stone incidence, while Abdolreza et $\mathrm{al}^{9}$ did. Overall, the results are inconclusive and there is still no strong evidence to prove or disprove this association. ${ }^{10}$ This study aims to shed light onto this question and help in solving this controversy. It also aims to take into consideration the seasonal variations (summer versus winter) in which Ramadan occurs, which has never been addressed or considered in previous studies. Furthermore, this study aims at investigating the patient factors associated with Ramadan and the site of the urinary tract stones. The objective of this study is to explore the incidence of urinary tract stones in the holy month of Ramadan compared to the other months and seasons of the year in patients admitted through the emergency department in 2 time periods: 1998-2002 (where Ramadan was in the winter) and 2011-2015 (where Ramadan was in the summer).

Methods. A retrospective cross-sectional study was conducted involving 237 consecutive urinary tract stone patients that presented, in 1998-2002 or 20112015, at the emergency department of King Abdulaziz Medical City, Riyadh, Kingdom of Saudi Arabia. The years 2003-2010 were excluded from the study because Ramadan did not lie in the summer or winter during those years.

The search method used to find prior related research involved a search of the PubMed and Google Scholar data sources. All articles that were published in the English language studying the effect of Ramadan fasting on the incidence of urinary tract stones were included.

Disclosure. Authors have no conflict of interests, and the work was not supported or funded by any drug company.
All patients included in this study were above the age of 18 years old and were admitted to the emergency department with a primary diagnosis confirmed clinically and radiologically (non-contrast CT scan) of urinary tract colic due to urinary tract stones. Urinary tract colic was defined as severe sudden flank pain, which most often radiates to the hypochondrium (the part of the anterior abdominal wall below the costal margins). The pain is colicky by nature and associated with nausea, vomiting and hematuria. ${ }^{11}$

In addition to socio-demographic characteristics (age, gender, nationality), other data related to the stone location (whether in the kidney, ureter, bladder, etc.), Ramadan versus non-Ramadan months, Ramadan in the summer versus in the winter, were also gathered.

Patients who were admitted with a diagnosis of urinary tract colic due to anything other than urinary tract stones (for example, infection), and patients who were found to have a urinary tract stone but were admitted to the wards for an alternative primary diagnosis (for example, not admitted through emergency department), were excluded from the study. Otherwise, all patients reported in the admission record and registered in the computer system of the hospital with the above-mentioned inclusion criteria were included in the study.

Summer months in the study city were defined as the months with the highest average temperature, which are: June, July, and August. Winter months were defined as the months with the lowest average temperature, which are: December, January, and February. Thus, day-time temperature in the summer ranged between 41-45 degrees Celsius while in the winter it ranged between 21-24 degrees Celsius. ${ }^{12}$

Ramadan months were selected according to the lunar calendar, which corresponded to the dates displayed in Table 1 within 2 different time periods. Ramadan in 1998-2002 was in the winter season, while in 2011-2015 was in the summer season.

The data were analyzed using the Statistical Package for the Social Sciences, version 20 (IBM Corp., Armonk, NY, USA). Numerical variables such as age were summarized and reported in terms of mean and standard deviation $( \pm S D)$. Categorical variables such as gender were summarized and reported in terms of frequency distribution. All categorical and interval variables were compared statistically across the study groups using Chi-Square test for categorical variables and t-test for interval variables. The frequency of urinary tract stones was compared between Ramadan in the summer, and Ramadan in the winter, and non-fasting months in the summer and winter for 1998-2002 and for 2011-2015. 
Table 1 - Ramadan months according to Lunar calendar and Gregorian calendar.

\begin{tabular}{lccc}
\hline Years & Ramadan & \multicolumn{2}{c}{ Non-Ramadan } \\
& & Summer & Winter \\
\hline $1998-1999$ & December 19 - January 18 & August & February \\
1999 -2000 & December 8 - January 8 & June & February \\
2000 & November 27 - December 12 & May & January \\
2001 & November 16 - December 16 & August & December \\
2002 & November 6 - December 5 & July & January \\
2011 & August 1 - 30 & July & December \\
2012 & July 20 - August 18 & June & January \\
2013 & July 9 - August 7 & June & February \\
2014 & June 28 - July 27 & August & December \\
2015 & June 18 - July 17 & August & January \\
\hline
\end{tabular}

Regression analysis was carried out to analyze the variance, its odds ratio 95\% CI. All statistical tests were declared significant at $\alpha$ level of less than 0.05 .

Ethical approval for the study was obtained from the institutional review board of the King Abdullah International Medical Research Center (KAIMRC) and data was dealt with carefully and confidentially. This study was performed according to the principles of the Helsinki Declaration.

Results. This study included 237 patients, 178 $(75.1 \%)$ were male and 59 (24.9\%) were female with the male to female ratio being approximately $3: 1$. The mean age of the patients was $45.8 \pm 16.2$ years, however, a higher rate of urinary tract stones was reported in those over 40 years old $(60.8 \%)$. The majority of the patients were Saudi (88.6\%), with only $11.4 \%$ being of non-Saudi origin, as seen in Table 2. Most of the stones in the patient population were located in the ureter $(72.2 \%)$, while the rest of the patients $(27.8 \%)$ had stones in other locations (for instance, kidney, bladder, urethra).

Table 3 shows the total number of urinary tract stone patients in the period from 1998-2002 and in the period from 2011-2015. There was no significant difference in the frequency of admission of urinary tract stone patients between Ramadan and non-Ramadan months in the period 1998-2002 $(p=0.527)$, or in the period 2011-2015 ( $p=0.208)$.

Table 4 shows the predicted factors associated with the location of the urinary tract stone. Patients fasting in Ramadan are twice as likely to present with stones in the ureter compared to another location $(p=0.016)$. There was no significant gender $(p=0.599)$ and age ( $p=0.475$ ) difference with regards to the location of the urinary tract stone.
Table 2 - Characteristics of the 237 consecutive urinary tract stone patients that presented, in 1998 to 2002 and 2011 to 2015.

\begin{tabular}{lrl}
\hline Variables & $\mathbf{n}(\%)$ \\
\hline Age (years) & (mean $45.8 ; \pm$ SD 16.2) \\
Age category & & \\
$\quad \leq 40$ years & 93 & $(39.2)$ \\
$\quad>40$ years & 144 & $(60.8)$ \\
Gender & & \\
$\quad$ Male & 178 & $(75.1)$ \\
Female & 59 & $(24.9)$ \\
Nationality & & \\
$\quad$ Saudi & 210 & $(88.6)$ \\
$\quad$ Non-Saudi & 27 & $(11.4)$ \\
Stone location & & \\
$\quad$ Ureter & $171 \quad(72.2)$ \\
Other & $43 \quad(27.8)$ \\
\hline
\end{tabular}

Bivariate analysis of the factors associated with urinary tract stones during Ramadan was carried out and showed a significant association with the summer season $(p=0.001)$, and being diagnosed with ureter stone $(p=0.014)$. The remaining factors like nationality, gender, age category over and less than 40 years old, and the 2 different time periods did not show any statistical significant associations.

As shown in Table 5, upon doing multivariate logistic regression, 3 independent variables associated with the diagnosis of urinary tract stones during Ramadan were found to be statistically significant: Saudi nationality, stone location in the ureter, and the summer season. The remaining items, such as gender, age category, and time period of the study, were not found to be significant in multivariate logistic analyses. The results indicate that Ramadan is an independent factor for the presence of stone in the ureter compared to other locations $(\mathrm{OR}=2.20)$. There were 4 times greater odds of the occurrence of urinary tract stones during Ramadan in the summer compared to winter $(\mathrm{OR}=4.38)$. Finally, being Saudi had 3 times greater odds of presenting with urinary tract stones during Ramadan compared to being non-Saudi $(\mathrm{OR}=3.32)$.

Discussion. The results of this study showed that the frequency of urinary tract stones did not significantly increase during Ramadan compared to non-Ramadan months within the same year, as seen in Table 3. This corresponds with what some of the previous studies have shown, for example; Miladipour et $\mathrm{al}^{8}$ prospectively studied 57 men, where they took measurements of urinary tract metabolites and looked at urinary tract 
Fasting in Ramadan \& risk of urinary stones ... Al Mahayni et al

Table 3 - Urinary tract stone occurrence in Ramadan and non-Ramadan months in 2 time periods.

\begin{tabular}{|c|c|c|c|c|c|c|c|}
\hline \multirow[t]{3}{*}{ Year } & \multicolumn{4}{|c|}{ Stone location } & \multicolumn{2}{|c|}{ Total } & \multirow[t]{3}{*}{$P$-value } \\
\hline & \multicolumn{2}{|c|}{ Ureter } & \multicolumn{2}{|c|}{ Other } & & & \\
\hline & $\mathbf{n}$ & $(\%)$ & $\mathrm{n}$ & $(\%)$ & $\mathrm{n}$ & $(\%)$ & \\
\hline $2011-2015$ & & & & & & & 0.208 \\
\hline Summer Ramadan & 53 & $(37.1)$ & 5 & (19.2) & 58 & (34.3) & \\
\hline Summer non-fasting & 41 & $(28.6)$ & 10 & $(38.5)$ & 51 & $(30.2)$ & \\
\hline Winter non-fasting & 49 & $(34.3)$ & 11 & $(42.3)$ & 60 & $(35.5)$ & \\
\hline Total & 143 & $(84.6)^{*}$ & 26 & $(15.4)^{*}$ & 169 & $(100.0)$ & \\
\hline $1998-2002$ & & & & & & & 0.527 \\
\hline Winter Ramadan & 8 & $(28.6)$ & 8 & $(20.0)$ & 16 & $(23.5)$ & \\
\hline Summer non-fasting & 11 & $(39.3)$ & 14 & $(35.0)$ & 25 & $(36.8)$ & \\
\hline Winter non-fasting & 9 & $(32.1)$ & 18 & $(45.0)$ & 27 & $(39.7)$ & \\
\hline Total & 28 & $(41.2)^{*}$ & 40 & $(58.8)^{*}$ & 68 & $(100.0)$ & \\
\hline & alc & ion $\mathrm{w}$ & & row total & & & \\
\hline
\end{tabular}

Table 4 - Predicted factors associated with location of urinary tract stone.

\begin{tabular}{|c|c|c|c|c|c|c|c|}
\hline \multirow[t]{3}{*}{ Variables } & \multicolumn{4}{|c|}{ Stone location } & \multirow[t]{3}{*}{ OR } & \multirow{3}{*}{$\begin{array}{c}95 \% \\
\text { confidence } \\
\text { interval }\end{array}$} & \multirow[t]{3}{*}{$P$-value } \\
\hline & \multirow{2}{*}{\multicolumn{2}{|c|}{$\begin{array}{l}\text { Ureter } \\
\text { n }(\%)\end{array}$}} & \multirow{2}{*}{\multicolumn{2}{|c|}{$\begin{array}{c}\text { Other } \\
\text { n } \quad(\%)\end{array}$}} & & & \\
\hline & & & & & & & \\
\hline \multicolumn{8}{|l|}{ Age } \\
\hline$\leq 40$ years & 69 & $(40.4)$ & 22 & $(33.3)$ & 1.250 & $0.678-2.307$ & 0.475 \\
\hline$>40$ years & 102 & $(59.6)$ & 44 & $(66.7)$ & (Ref.) & - & - \\
\hline \multicolumn{8}{|l|}{ Gender } \\
\hline Male & 130 & $(76.0)$ & 48 & $(72.7)$ & 0.841 & $0.441-1.604$ & 0.599 \\
\hline Female & 41 & $(24.0)$ & 18 & $(27.3)$ & (Ref.) & - & - \\
\hline \multicolumn{8}{|l|}{ Fasting } \\
\hline Ramadan & 62 & $(36.3)$ & 13 & $(19.7)$ & 2.319 & $1.172-4.587$ & $0.016^{*}$ \\
\hline Non Ramadan & 109 & $(63.7)$ & 53 & $(80.3)$ & (Ref.) & - & - \\
\hline \multicolumn{8}{|c|}{${ }^{*}$ Significant $p<0.05, \mathrm{OR}$ - odds ratio } \\
\hline
\end{tabular}

Table 5 - Univariate and multivariate regression analysis for factors associated with the occurrence of urinary tract stones during Ramadan.

\begin{tabular}{|c|c|c|c|c|c|c|}
\hline Variables & OR & $95 \% \mathrm{CI}$ & $\mathrm{P}$-value & AOR & $95 \% \mathrm{CI}$ & $P$-value \\
\hline \multicolumn{7}{|l|}{ Nationality } \\
\hline Saudi & 3.321 & $1.320-8.356$ & $0.011^{*}$ & 3.610 & $1.438-9.060$ & $0.006^{*}$ \\
\hline Non-Saudi & (Ref.) & - & - & - & - & - \\
\hline \multicolumn{7}{|l|}{ Gender } \\
\hline Male & 1.731 & $0.871-3.439$ & 0.117 & - & - & - \\
\hline Female & (Ref.) & - & - & - & - & \\
\hline \multicolumn{7}{|l|}{ Age } \\
\hline$\leq 40$ years & 1.287 & $0.700-2.365$ & 0.416 & - & - & - \\
\hline$>40$ years & (Ref.) & - & - & - & - & - \\
\hline \multicolumn{7}{|l|}{ Stone location } \\
\hline Ureter & 2.201 & $1.095-4.870$ & $0.017^{*}$ & 1.980 & $0.961-4.077$ & 0.064 \\
\hline Other & (Ref.) & - & - & - & - & - \\
\hline \multicolumn{7}{|l|}{ Season } \\
\hline Summer & 4.381 & $2.209-8.688$ & $0.000^{*}$ & 4.563 & $2.322-8.968$ & $0.000^{*}$ \\
\hline Winter & (Ref.) & - & - & - & - & - \\
\hline \multicolumn{7}{|l|}{ Time period } \\
\hline $1998-2002$ & 1.142 & $0.524-2.489$ & 0.738 & - & - & - \\
\hline 2011-2015 & (Ref.) & - & - & - & - & - \\
\hline
\end{tabular}


Table 6 - Factors associated with location of urinary stone.

\begin{tabular}{|c|c|c|c|c|c|}
\hline \multirow[t]{2}{*}{ Variable } & \multirow{2}{*}{\multicolumn{2}{|c|}{$\begin{array}{c}\text { Ureter stone } \\
\text { n (\%) }\end{array}$}} & \multicolumn{2}{|c|}{ Others } & \multirow[t]{2}{*}{$P$-value } \\
\hline & & & $\mathrm{n}$ & $(\%)$ & \\
\hline Gender & 130 & $(76.0)$ & 48 & $(72.7)$ & 0.599 \\
\hline \multicolumn{6}{|l|}{ Male } \\
\hline Female & 41 & $(24.0)$ & 18 & $(27.3)$ & \\
\hline \multicolumn{6}{|l|}{ Age category } \\
\hline$\leq 40$ years & 69 & $(40.4)$ & 22 & $(33.3)$ & 0.319 \\
\hline$>40$ years & 102 & $(59.6)$ & 44 & $(66.7)$ & \\
\hline \multicolumn{6}{|l|}{ Nationality } \\
\hline Saudi & 153 & $(89.5)$ & 57 & $(86.4)$ & 0.499 \\
\hline Non-Saudi & 18 & $(10.5)$ & 9 & $(13.6)$ & \\
\hline \multicolumn{6}{|l|}{ Season } \\
\hline Summer & 105 & $(61.4)$ & 29 & $(43.9)$ & $0.015^{*}$ \\
\hline Winter & 66 & $(38.6)$ & 37 & $(56.1)$ & \\
\hline \multicolumn{6}{|l|}{ Summer } \\
\hline Fasting Ramadan & 53 & $(31.0)$ & 5 & (7.6) & $0.001^{*}$ \\
\hline \multicolumn{6}{|l|}{ Winter } \\
\hline Fasting Ramadan & 8 & $(4.7)$ & 8 & (12.1) & \\
\hline \multicolumn{6}{|l|}{ Summer } \\
\hline Non-Ramadan & 52 & $(30.4)$ & 24 & $(36.4)$ & \\
\hline \multicolumn{6}{|l|}{ Winter } \\
\hline Non-Fasting & 58 & $(33.9)$ & 29 & $(43.9)$ & \\
\hline \multicolumn{6}{|c|}{$*$ Significant $p<0.05$} \\
\hline
\end{tabular}

stone precipitating solutes and inhibitory factors before and during Ramadan. They concluded that there wasn't enough evidence to suggest that there is an increased risk for urinary tract stone during Ramadan. Al-Hadramy ${ }^{6}$ retrospectively studied records of patients admitted to the emergency department with urinary tract stone colic, and he concluded that the increased rate of admission due to urinary tract stone colic is seen in hot months in general, but not during Ramadan. Another study also retrospectively investigated 574 records of patients admitted to medical centers for urinary tract colic, and they also came to the conclusion that a higher temperature rather than Ramadan fasting caused an increased rate of admission during hot months. ${ }^{7}$ Bragazzi and Luigi ${ }^{1}$ performed a systematic review and after summarizing the collected evidence (1,262 patients), concluded that Ramadan did not alter the balance between urinary tract stone promoting and inhibiting factors. A similar study prospectively investigated 176 patients before and during Ramadan who were admitted to the emergency department with urinary tract colic, and they concluded that Ramadan fasting did not affect the number of admissions. ${ }^{13} \mathrm{On}$ the contrary, Abdolreza et $\mathrm{al}^{9}$ showed that the number of admissions due to urinary tract colic was higher during the first 2 weeks of Ramadan compared to before Ramadan, but then decreased during the last 2 weeks of Ramadan. They also mentioned that the climate and humidity might have had a role in this trend, so their study was inconclusive. ${ }^{?}$

Therefore, our study confirmed that Ramadan does not independently increase the incidence of urinary tract stones, while also taking into consideration the seasonal variations of Ramadan thus giving stronger evidence to the claim.

This study also shows that there is a significant association between ureter stone location and Ramadan in the summer season, as seen in Table 6. This could indicate an effect of hot climate in the summer season. This also conforms with previous studies as $\mathrm{Taha}^{2}$ concluded that higher temperatures rather than Ramadan fasting appeared to be a risk factor for urinary tract stones. Boscolo-Berto et $\mathrm{al}^{14}$ concluded that there is an association between hot and dry climate and increased urinary tract stone formation. A different study also concluded that urinary tract stone admissions increased during the hottest months of the year, and started declining starting from Septemer. ${ }^{15}$ Finally, Cervellin et $\mathrm{al}^{16}$ also analyzed data and confirmed a peak incidence of urinary tract stones during the summer. These findings may be explained by the fact that hot climate can increase the chances of dehydration and decreased urine volume in patients, predisposing them for urinary stone formation. To avoid dehydration during Ramadan, people who are fasting are recommended to always stay hydrated and drink enough water throughout the evening, especially during the hot summer months. This may lower the incidence of urinary tract stones during Ramadan, especially in the summer.

Another interesting finding is that stone location is significantly associated with Ramadan months, where during Ramadan urinary tract stones are more likely to form in the ureter than in other locations of the urinary tract, as seen in Tables 4 \& 5. This has not been mentioned in previous literature, and more studies were carried out prospectively are needed to confirm this finding. Finally, it was shown in Table 5 that Saudi nationality is independently associated with urinary stone formation during Ramadan. This might be explained by the fact that most of the Saudi nationals above the age of 18 would be fasting during Ramadan, while some of the non-Saudi nationals who are not Muslim will not be fasting during Ramadan. The implications of the findings of this study for future research include the need to do prospective studies which document fasting status of the patients, and further study the risk factors for location of the urinary stone and occurrence of urinary stones in Ramadan.

The limitations of this study were: 1 ) This study is retrospective, thus we assumed, given that most of the 
patients were Saudi (Muslim) and above the age of 18, that they were all fasting during the month of Ramadan, but this was not confirmed. Thus, we recommend a prospective study with documented fasting status in order to confirm this study's results; 2)This study is a cross-sectional study, and thus cannot establish causality, but just aimed to look for any association between Ramadan and urinary tract stone incidence; 3) The total number of patients in the period from 1998-2002 was just 68 patients compared to 169 patients in the 2011-2015 period. This could be explained by data registry discrepancy and improved diagnostic imaging and procedures in the latter period.

In conclusion, fasting in Ramadan does not increase the risk for developing urinary tract stones compared to non-fasting months. However, fasting in Ramadan during the summer may increase the risk of developing ureter compared to fasting in Ramadan during the winter. This can be justified by the fact that hot climate can increase the chances of dehydration and decreased urine volume in patients, predisposing them for urinary stone formation. Finally, urinary tract stones are more likely to form in the ureter during Ramadan than in other locations of the urinary tract. This has not been mentioned previously in the literature, and warrants further prospective studies.

Acknowledgment. We would like to thank American Manuscript Editors for their English language editing service.

\section{References}

1. Bragazzi NL. Ramadan fasting and chronic kidney disease: A systematic review. J Res Med Sci 2014; 19: 665-676.

2. Taha I. Renal diseases and Ramadan: A review of the literature. Life Sci J 2013; 10.

3. Azizi F. Research in Islamic fasting and health. Ann Saudi Med 2002; 22: 186-191.

4. Zghal A, Fellah H, Zerelli L, Daudon M, Belkehia C, Ben Ammar S. Variation of biochemical parameters of the first morning urine during month of Ramadan. Tunis Med 2005; 83: $591-594$
5. Shafiee MA, Aarabi M, Shaker P, Ghafarian AM, Chamanian $\mathrm{P}$, Halperin ML. Impact of prolonged fasting on the risk of calcium phosphate precipitation in the urine: calcium phosphate lithogenesis during prolonged fasting in a healthy cohort. J Urol 2018.

6. al-Hadramy MS. Seasonal variations of urinary stone colic in Arabia. J Pak Med Assoc 1997; 47: 281-284.

7. Basiri A, Moghaddam SM, Khoddam R, Nejad ST, Hakimi A. Monthly variations of urinary stone colic in Iran and its relationship to the fasting month of Ramadan. J Pak Med Assoc 2004; 54: 6-8.

8. Miladipour AH, Shakhssalim N, Parvin M, Azadvari M. Effect of Ramadan fasting on urinary risk factors for calculus formation. Iran J Kidney Dis 2012; 6: 33-38.

9. Abdolreza N, Omalbanin A, Mahdieh TS, Mohammad Ali MR, Reza MS, Maryam S, et al. Comparison of the number of patients admitted with renal colic during various stages of peri-Ramadan month. Saudi J Kidney Dis Transpl 2011; 22: 1199-1202.

10. Emami-Naini A, Roomizadeh P, Baradaran A, Abedini A, Abtahi M. Ramadan fasting and patients with renal diseases: A mini review of the literature. J Res Med Sci 2013; 18: 711-716.

11. Schulsinger DA. Kidney Stone Disease: Say NO to Stones! 1 st ed: Springer; 2014.

12. Römer U. WeatherOnline - Meteorological Services UK2018. Available from: https://www.weatheronline.co.uk/weather/ maps/city.

13. Cevik Y, Corbacioglu SK, Cikrikci G, Oncul V, Emektar E. The effects of Ramadan fasting on the number of renal colic visits to the emergency department. Pak J Med Sci 2016; 32: 18-21.

14. Boscolo-Berto R, Dal Moro F, Abate A, Arandjelovic G, Tosato F, Bassi P. Do weather conditions influence the onset of renal colic? A novel approach to analysis. Urol Int 2008; 80: 19-25.

15. Naeem M, Hazratullah MKK, Khan RA, Ahmad I, Asif M. Frequency of renal colic due to renal stone associated with change in climate during different months of the year. J Saidu Med College 2013; 3: 2.

16. Cervellin G, Comelli I, Comelli D, Meschi T, Lippi G, Borghi L. Mean temperature and humidity variations, along with patient age, predict the number of visits for renal colic in a large urban Emergency Department: results of a 9-year survey. J Epidemiol Glob Health 2012; 2: 31-38. 